\title{
LOWER LEG OVERUSE INJURIES IN HIGH SCHOOL FIRST TEAM SCHOOLGIRL HOCKEY PLAYERS
}

\section{Petrick M, Laubscher KF, Peters EM University of Witwatersrand \\ INTRODUCTION}

During the second half of 1989 the Division of Physical Education of the Witwatersrand received communication from the Griqualand-West Schools Hockey Union (GWSHU), expressing their concern about the high incidence of "shin splints" amongst the hockey players during that season and requesting an investigation into this matter.

The American Medical Association defined "shin splints" as a musculotendinous inflammation, in the absence of a stress fracture or ischaemic disorder, manifesting with "pain and discomfort in the leg from repetitive running on a hard surface or forcible, excessive use of foot flexors"' . As lower leg pain can be caused by a spectrum of pathological conditions in the lower leg including stress fractures, compartment syndromes and various presentations of musculotendinous inflammation, the authors undertook a survey investigating the incidence of hockey injuries with specific emphasis on these three forms of lower leg pain.

In view of the contrasting environmental and training factors to which high school players in the Southern Transvaal (ST) and Griqualand West (GW) regions are exposed, it was decided to undertake a comparative study of the incidence and nature of lower leg injuries amongst high school players in the hockey leagues in these two regions.

The objective of this study was twofold: firstly, to identify which of the lower leg overuse injury risk factors are most prevalent amongst female first team high school hockey players in the ST and GW regions and, secondly, to establish whether contrasting environmental factors predispose players in the two regions to different injuries.

\section{METHOD}

Questionnaires were sent to the first team female hockey players of the top seven teams in the GW High School Hockey League (the experimental group) and to the seven best hockey teams in the ST High School Hockey League (the control group) in 1990. The questionnaires elicited information regarding history of orthopaedic problems, involvement in other sport, hockey training (eg. methods, playing surface, shoe wear) and an injury profile.
Players who reported having suffered from lower leg pain during the 1990 season were requested to provide further details with regard to footwear pattern, shape of wet footprint, shoe types worn when playing hockey and a description of the lower leg pain. In order to differentiate between the different lower leg injuries, those players who could localise a very tender spot and described focal pain on the shin bone were diagnosed as possessing a stress fracture ${ }^{l}$. Those that complained of pins and needles and numbness and those that reported experiencing weakness of the leg were categorised into a group possibly possessing compartment syndrome ${ }^{1}$, whereas the remainder were, in keeping with the definition of the American Medical Association, regarded as possessing shin splints. The use of the word "shin splints" in this paper is limited to the definition provided by the American Medical Association.

Additional sports participated in by the first team hockey players were categorised into activities possessing a low or high risk for shin splints, depending on the magnitude, frequency and duration of impact loading which is characteristic of each of the sports.

The coaches of each of the teams also received a short questionnaire requesting details regarding their coaching techniques or protocols and were asked to keep an attendance register of their players for both practices and matches. They were also asked to record any hockey injuries their players sustained during the 1990 hockey season. All questionnaires were completed during August and September 1990.

\section{Statistical Analysis:}

For discrete variables, groups were compared using the chi-square test to analyse contingency tables where the sample sizes and expected frequencies were adequate. Where sample sizes and expected frequencies were too small, Fisher's exact test was employed in the case of $2 \times 2$ tables. For continuous variables, groups were compared using student's t-test, taking into account whether the variances of the groups were equal of not. Where appropriate, the Man-Whitney test was used. In all cases, the level of confidence was set at 0,05 .

\section{RESULTS}

\section{PLAYERS:}

Seventy five ST and $81 \mathrm{GW}$ first team hockey players completed the players' questionnaire. Their mean age was 16 years. Seventy five players reported sus-

\section{ABSTRACT}

Questionnaires eliciting training histories and injury profiles were sent to the first team female hockey players and coaches of the top seven hockey schools in the Griqualand West and Southern Transvaal high school leagues during the 1990 hockey season.

During this season, $27,4 \%(n=43)$ of the players reported that they had experienced pain in the lower leg area. The findings of this study suggest that some degree of pes planus may be a common problem and that the wearing of hockey boots may reduce the risk of lower leg pain. A general lack of knowledge about lower leg overuse injuries and their prevention was apparent amongst the players. The need for education on these injuries and their prevention was identified and recommendations for closer liaison between coaches and players were made. (Key Words: shin splints; hockey; high school girls)

\section{OPSOMMING}

Gedurende die 1990 Suid-Afrikaanse hokkieseisoen is vraelyste aangaande oefengeskiedenis en beseringsprofiele aan die eerstespan hokkiespeelsters en afriglers van die sewe beste hokkiespanne in die hoërskole-hokkieliga van Suid-Transvaal en Griekwaland-Wes gestuur.

In bogenoemde seisoen het $27,4 \%(n=43)$ van die speelsters aangedui dat hulle pyn in die onderbeen ervaar het. Die bevindinge van hierdie navorsing dui daarop dat ' $n$ mate van pes planus'n algemene probleem mag wees en dat die dra van hokkieskoene die risiko van onderbeenpyn mag verminder.

Algemene onkunde aangaande oorgebruik-onderbeen beserings en die voorkoms daarvan is by die speelsters gevind. Die behoefte aan oplaiding aangaande hierdie beserings en hulle voorkoming is geïdentifiseer en voorstelle om beter kommunikasie tussen spelers en afrigters te bevorder, is gemaak.

taining injuries during their hockey careers. Of the total sample $(n=157), 43$ $(27,4 \%)$ had experienced lower leg pain in the 1990 season, which excluded ankle injuries and extrinsic injuries and direct trauma to the lower leg area.

The diagnosis and presentation of lower leg pain in these players is depicted in Figure 1 (page 57). In $34 \%(n=14)$ of the players, shin splints was diagnosed by a medical practitioner. Fifty nine percent $(n=26)$ of the players did not seek medical advice (Figure 1.1). Anterior lower leg was by far the most common, with a total of $74 \%(n=32)$ of the players complaining of pain in this anatomical location (Figure 1.2). The percentage of players describing their lower leg pain as being on the shin bone, in the muscles or in both areas is illustrated in Figure 1.3.

Fifty six percent $(n=24)$ of the players with lower leg pain reported "bumps" on

Continued on page $57 .$. 


\section{COME FO AMERICA WE NEED QUALIEIED THERAPISTS}

If you have a sincere interest in traveling to America to practice Physiotherapy or Occupational therapy, consider Maxwell/Healthcare Inc for general options:

- As an employee of Maxwell/Healthcare you will travel as a long term/short term locum therapist.

- Be employed as a full time staff therapist by one of our client hospitals, rehab centers, sport medicine clinics.

Maxwell/Healthcare Inc. has a proven history of high professional standards. We have the administrative staff with strong healthcare backgrounds from Human Resource to Healthcare Administration - a desired quality when matching the therapist to the preferred Healthcare facility.

Maxwell/Healthcare is active in the Philippines, Australia, New Zealand, Canada, England and Ireland. We have the staff and experience to serve the needs of the therapist as well as our client throughout the United States of America.
You will receive an excellent salary and benefit package. In addition, all therapists will be contratually guaranteed:

- Paid airfare to America and place of employment.

- Paid housing, furniture and utilities for $\mathbf{6 0 - 9 0}$ days.

- Travelling therapists receive paid housing and meal allowance for each assignment.

- Paid health / life insurance.

- Paid professional liability coverage.

- Paid immigration processing.

- Paid state board review programs to prepare for national exams.

Maxwell/Healthcare has representatives in the Republic of South Africa to assist in all paperwork and timely follow-through.

A career in America is not perfect - nothing is, but with the right start, it can be very rewarding.

IF YOU HAVE A SINCERE INTEREST AND WOULD LIKE A PERSONAL INTERVIEW WITH THE PRESIDENT AND V.P OF OPERATIONS OF MAXWELL HEALTHCARE CONTACT:

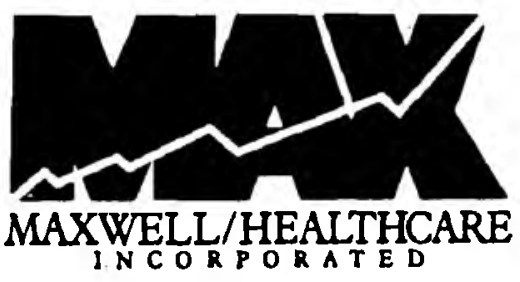

8221 East 63rd Place, Tulsa, Oklahoma, USA 74133
Palte \& Associates Inc.

Andrea Bernstein

c/o P.O. Box 37002

Overport 4067

R.S.A

(031) 253630 telephone

(031) 297072 fax 


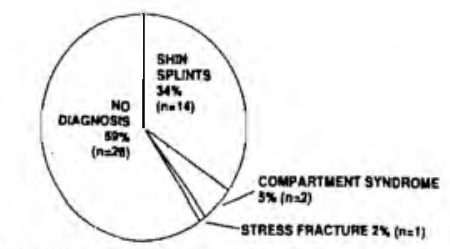

1.1 OAAGNOSIS BY MEDICAL PRACTITONER

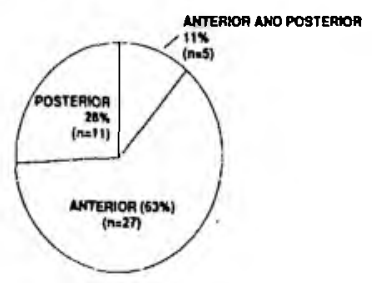

1.2 AMATOMCAL LOCATION OF REPORTED LOWEA LEG PAIN

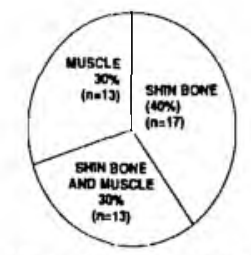

1.3 IISSUE SITE OF LOWER LEQ PAIN

Figure 1: Diagnosis and presentation of lower leg pain in schoolgirl hockey players

the shin bone and $48 \%(n-20)$ could localise one very tender spot on the shin bone. Swelling and tenseness of the muscles of the front of the lower leg was experienced by $59 \%(n=24)$ of the symptomatic players, whereas $40 \%(n-17)$ experienced a "pins and needles" sensation or numbness associated with the lower leg pain and $46 \%$ $(n=19)$ had weakness in the affected leg.

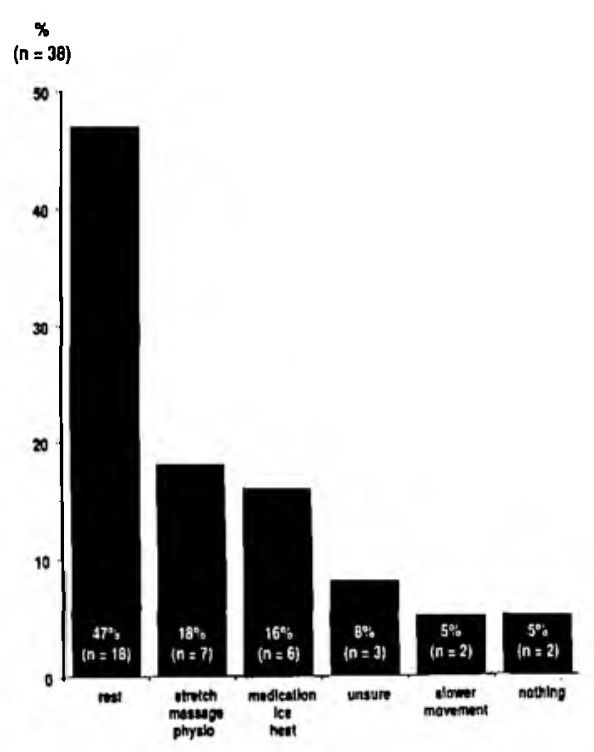

Figure 2: Methods employed by hockey players to ease lower-leg pain

With regard to the frequency and the duration of the lower leg pain, $88 \%(n=37)$ of the symptomatic players had experienced the lower leg pain more than twice; $51 \%(n-21)$ reported that the pain lasted less than an hour, while $29 \%(n-12)$ experienced the pain for a few hours or longer. The mean duration of the pain was just less than an hour. Thirty percent (n-11) were unsure about the cause of this pain. Nineteen percent (n-7) attributed the pain to "shin splints" and 14\% ( $n=5)$ suggested that the lower leg pain was due to overexertion of the legs. Eleven percent $(n=4)$ listed the type of surface played on as a major etiological factor.

With regard to the occurrence of lower leg pain, $77 \%$ ( $n-33$ ) of the symptomatic players reported that this pain was associated with playing hockey. Of the total group of symptomatic players questioned, $36(92 \%)$, however, reported pain while playing hockey, whereas $30(83 \%)$ reported that the pain persisted after the cessation of hockey play.

Twenty two players (58\%) reported that running made the pain worse. Eleven $(29 \%)$ described a worsening of pain with an increase in activity or over-exertion, whereas two players $(5 \%)$ maintained that a quick change in direction worsened the pain. The pain relief modalities used by players are categorised in Figure 2. In addition, $33(85 \%)$ of the players continued with the activity when the pain started while five $(13 \%)$ ceased the activity. The areas of the soles of the hockey shoes most worn were the medial front parts of the shoes $(66 \% ; n=25$ on both left and right), whereas the lateral front parts of the soles were worn away in $50 \%(n=19)$ on both left and right shoes. The most frequently occurring shape of a wet footprint for both the left and right foot identified first degree pes planus ${ }^{2}$ (Figure 3 ).

When comparing the ST and GW players in our sample, no significant difference in the incidence of lower leg pain was found in the 1990 season $(25,3 \%$ of ST first team hockey players vs. $29,3 \%$ of the GW players had lower leg pain).

Of the 157 players questioned, significantly more players $(p, 05)$, who presented with lower leg pain $(n=43)$, reported leg problems $(n=12)$ than those without lower leg pain $(n=1)$. Significantly more $(p, 05)$ players with lower leg pain also had knee problems $(25,6 \%)$ than players without lower leg pain $(11 \%)$. Of the players with knee problems, $47,8 \%$ also reported lower leg pain.

No significant difference was found in the number of sports participated in by players with and without lower leg pain. Furthermore, no correlation was found between participation in additional sports with low or high risk of developing lower leg pain and the reported incidence of lower leg pain. In addition, no significant difference was found in the incidence of lower leg pain between those who did not participate in other sports and those who did $(p 0,05)$.
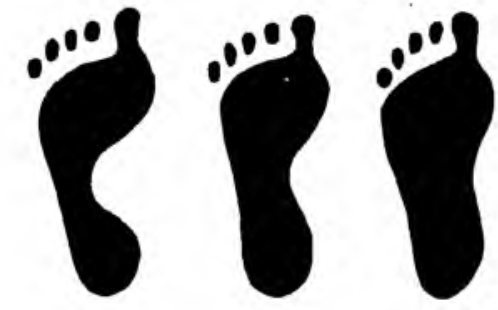

normal toot

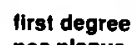
pes planus

second degree pes planus

lett: $32 \%(n=12)$ rlght: $32 \%(n=12)$

lott: $42 \%(n=16)$ left: $26 \%(n=10)$

\section{Figure 3: Various degress of pes planus}

A highly significant difference $(p, 01)$ was found between the number of players with lower leg pain wearing hockey boots $(69,8 \%)$ and the players without lower leg pain wearing hockey boots $(90,1 \%)$. Significantly $(p, 05)$ more players with lower leg pain had hockey injuries $(65 \%)$ than players without lower leg pain (44\%). A significant difference $(p, 05)$ was found in the number of injuries per person, comparing those with lower leg pain to those without. Of those that indicated no injuries, only $34,9 \%$ had lower leg pain. Of those indicating one injury, equal amounts had lower leg pain $(27,9 \%)$ than did not have lower leg pain $(29,8 \%)$. Of the players that indicated two or more injuries, $37,2 \%$ had lower leg pain, while $14 \%$ did not have lower leg pain. A significant difference was found between the incidence of lower leg pain between those with no and one injuries and those with two to four injuries $(\mathrm{p}, 01)$.

\section{COACHES}

Twelve coaches completed the questionnaire. Eighty three percent $(n=10)$ of the coaches had completed hockey instructors courses and examinations, with $55 \%$ $(n-7)$ of the coaches having had more than ten years of coaching experience and $83 \%$ (n-10) having played at provincial or international level.

The coaches reported their players to have sustained a total of 30 injuries in the 1990 season. The most common injury reported by the coaches was lower leg overuse injury (n-13). The most common injury reported by coaches in the ST was "shin splints" or lower leg pain $(62,8 \%$ of the injured players), whereas only $30,6 \%$ of the injured first team players of the GW were reported to have the above complaint.

\section{DISCUSSION}

The concern about the high incidence of shin splints amongst school girl hockey players in the GW area during the 1989 season, led us to expect a higher incidence 


\section{PHYSICAL AND OCCUPATIONAL THERAPISTS}

\section{Hundreds of positions available immediately, in any state - Florida, Texas, New England ...}

"MRI found us a wonderful job in a traveling program. Our first assignment was in Las Vegas, Nevada, then we were off to Rbode Island. We wanted to see the United States and get experience. Tbanks to MRI, we are doing both. Everyone bas been so nice to us."

-Annalie Van Zyl and Annelu Van Wyk<smiles>C1C[C@H]2C[C@@H]1C2</smiles>
edical Resources Intermational can place you in any specialty in any part of 1 the Unired States - at $\$ 35,000$ to $\$ 60,000$ a year. Your licensure and credentialing and visa fees are fully paid.

PLUS: we provide a FREE study course and materials to help you pass the state board exams.
We hire in all specialties, including:

- Clinical Coordinatcrs and staff positions

- Outpatient orthopedics/Sports medicine

- Rehab, including neuro, cardiac, and brain injury

- Acute care $\square$ Pediatrics

- Work hardening I Geriatrics

See the U.S. - Apply for one of our traveling positions:

- Work in a variety of locations

- Company car a Housing subsidy

- Salaries $\$ 40$ to $\$ 50,000$

- Travel to a new sate every three months

Other services:

- FREE Air fare - Housing assistance

- Medical, life, and professional insurance

Medical Resources InternationalMore Jobs, Better Service

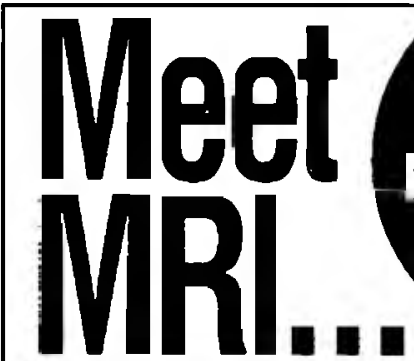

Over 200 health care professionals placed this past year

FRIE PRESENTYITINSO

"Living and Working in the USA"

- Capetown $\square$ Tygerberg

- Pretoria Durban

- Johannesburg

- Bloemfontein

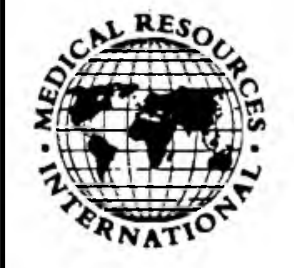

Presentations to be beld in late September. Please call for exact dote and time.

\section{CALl us COLLECT 5154724018}

For presentation dates and times

Offices in Australia, U.K., Holland, Poland, Philippines, and U.S.A.

Medical Resources International, Ltd. 101 N. Main St., Suite 202, Fairfield, IA 52556 U.S.A. • Fax (515) $472-1897$ 


\section{continued from page 57}

of lower leg overuse injuries amongst the GW players when compared to players in the ST. The difference was however, not found to be sta tistically significant. Despite the high incidence of "shin splints" reported amongst high school players in GW during the 1989 season, the incidence dropped during the 1990 season. A possible factor to which this could be attributed is that greater awareness of the risk factors of lower leg injury among the hockey fraternity led to more precautions being taken.

It is well documented that doing too much, too soon and too hard all play a role in the aetiology of these intrinsic lower leg injuries ${ }^{1,3}$ as well as the frequent changes of direction and jarring on the lower leg which are common to the game of hockey ${ }^{4}$. Excessive strain on the tibia due to the pounding action of prolonged running on a hard surface is known to constitute a risk factor for stress fractures ${ }^{5,6,7}$. It is when the compressive force associated with weight bearing exceeds the structural strength of the bone that micro-fractures of bone result ${ }^{5,6}$. Compartment syndrome may however, arise following extrinsic injury (a direct blow to the shin) or due to intrinsic overuse inflammation in a tight compartment $^{1}$. Shin splints is most commonly caused by excessive pronation of the foot, where tendinitis or periostitis develops from excessive rotational stress on the muscles of the anterior tibial and deep posterior compartments of the lower leg, which control pronation ${ }^{8}$. It is in particular the pes planus foot which possesses hypermobility in the subtalar joint and which is inclined to hyperpronate on landing and not supinate on take-off, that leads to shin splints $1,8,6,3$. Hyperpronation may also be a result of inappropriate footwear, too resilient a playing surface, imbalances in muscle strength and flexibility and skeletal malalignment. Uneven terrain and hard landing surfaces have been associated with musculotendinous inflammation in the anterior and deep posterior compartments of the lower leg $1,7,6$. Moore, emphasises the fact that a combination of insults on the muscle-tendon unit may exceed the reparative capability of the muscle-tendon unit, leading to overuse injuries ${ }^{8}$. Biomechanical imbalances resulting from skeletal malalignment such as excessive femoral anteversion, an increased Q-angle, external tibial torsion, valgus heels and tarsal coalition also predispose to intrinsic lower leg injury ${ }^{6}$. Over-exertion without proper conditioning has also been described as playing a role in the aetiology of shin splints $1,10,9$

Backx ${ }^{11}$ et al states that the more one participates in sports, the higher the risk of injury but this was not confirmed by the findings of this study. It was, however, found that the more injuries a player had sustained, the higher the likelihood of lower leg pain, due possibly to the fact that, in compensating for the injured part, $a b$ normal biomechanical forces may be exerted on other anatomical structures.

In our study, the symptomatic players described a pattern of shoe wear that may indicate some pronation of the feet. The wearing of hockey boots also appears to reduce the risk of lower leg overuse injuries, dua to greater stability of the floor. The studs on the soles increase the grip on the playing surface, thereby facilitating the quick changes in direction and stop-start actions necessary to hockey. The forces on the muscles of the lower leg are thus reduced during accelerating and decelerating actions, thereby lessening the risk of shin splints. Hockey boots may also provide some shock absorption and reduce the pounding on the tibia. Of interest is the fact that all coaches in this study advocated the use of hockey boots.

Michael and Holder ${ }^{12}$ state that the soleus inserts medially into the calcaneus and is therefore elongated when the heel pronates. A prolongation of the pronation time will therefore increase the eccentric loading of the soleus muscle, resulting in injury ${ }^{13}$. Hockey players who pronate excessively may therefore benefit from wearing orthotics ${ }^{14}$ or from wearing hockey boots.

The lower leg pain associated with hockey was worsened by running, an increase in activity or over-exertion. Rest helped to ease the pain in most cases. According to Moore, shin splints pain is initially mild, develops during exercise and is eased by rest $^{8}$. With continued exertion, pain progressively worsens. The fact that most players with lower leg pain in our study did not cease the pain-provoking activity indicated a lack of awareness of the importance of preventing aggravation of an injury by either resting, reducing the intensity of the pain-provoking activity or by correcting the etiological factors.

Garrick et $a l^{15}$ sta te that a history of prior orthopaedic problems and the lack of involvement in other fitness activities were more likely to cause aerobic dance injury than shoe brand or type of flooring. Our findings, however, clearly support the contention that players with lower leg pain were more likely to have leg or knee problems than those without lower leg pain. Of the players with knee problems in this study, 47,8\% also had lower leg pain. This may be indicative of a possible relationship between knee problems and lower leg pain or, alternatively, the presence of a common factor, causing both knee and lower leg pain. It is well accepted that structural abnormalities, when analysed biomechanically, can result in unbalanced forces on the soft tissue structures of the lower leg and may predispose to lower leg pain.

Training errors play an important role in the aetiology of shin splints ${ }^{8}$. As a whole, the coaches were well qualified with extensive hockey coaching experience. Coaching methods such as pre-season training of shorter duration than the training in season and the emphasis on pre-season endurance training were applied. In addition, all coaches included a pre-season and in-season stretching programme which was executed before training and matches, which is essential for the prevention of injury ${ }^{16}$. Repetitive concentric muscle contractions lead to muscle hypertrophy and shortening ${ }^{17}$. Therefore, as muscles are strengthened, they also need to be stretched regularly, in order to maintain their length and flexibility ${ }^{17}$. The fact that players did not stretch after practices or matches does give rise to concern, since this can lead to a higher risk of overuse injury ${ }^{18}$.

In a typical hockey practice, most time was spent on stickwork, followed by combinations of sprinting and jogging, and dribbling. It is, however, of concern that players did not realise the importance of becoming fit for their sport before the season starts. Using the actual sport as a means of becoming fit places the player at a high risk of injury as a sudden demand will be placed on untrained muscles. Lehman ${ }^{10}$ states that there is a fine line between stress placed on the body producing the desired training effect and training that overstresses, causing injury. It is therefore advisable to start a gradual fitness programme before the hockey season commences.

In order to prevent injury, an ideal warm up before a match should include jogging and stretching in addition to specific hockey techniques such as stickwork. Jogging will increase the blood flow to the muscles, and the warmed muscle fibres can bestretched more effectively, thus producing a prolonged elongation effect. Specific hockey techniques also have a place in a warm up as they will improve the neuromuscular coordination needed for the activity to follow. The low number of players indicating the inclusion of stretching or jogging in their warm up may be an indication that players were not aware of the importance of these elements in any warmup.

The external environment also plays a role in the aetiology of shin splints ${ }^{7,6}$. Both teams played on grass surfaces most frequently. The players from GW also play on soil more frequently than their ST counterparts. Poor shock absorption occurs when running on a hard surface and more of the impact will be exerted on the legs. Our findings did not however, show a significant difference in the incidence of lower leg continued on page 60 .. 
injuries between the two regions in 1990 . This may be due to more players in GW wearing hockey boots during the 1990 season.

When compared with the players, the coaches r'sported a much lower incidence of hockey injuries sustained in the 1990 season. Of the players, $43(27 \%)$ alone indicated a problem with lower leg pain in $1990,33(22 \%)$ indicating that the lower leg pain was associated with hockey. According to the coaches, more ST than GW players had lower leg pain or "shin splints" in the 1990 season. The coaches underestimated the number of players with lower leg pain and according to the information gained from the players, no significant difference $(p 0,05)$ was found in the incidence of lower leg pain between ST and GW in 1990.

It thus appear to be a lack of awareness by both the coaches and players of the incidence of lower leg overuse injury amongst hockey players.

\section{CONCLUSION}

From the findings of this study the following conclusions have been reached:

- A common lack of knowledge about overuse injuries, their cause and their prevention was evident amongst the players. Not all the players were able to recognise the onset of an overuse injury and players were unaware of the importance of modifying their training and activity levels. The need for education on overuse injuries must therefore be emphasised.

- Players were not adequately aware of the importance of

* getting fit before the start of the hockey season, and

\section{IN MEMORIAM - WILLIAM EDGAR GEORGE VAUGHAN} (1920-1993)

Born in Ammanford, Wales and trained at the Field and Morris School of Physiotherapy, London.

At the outbreak of war Eddie volunteered as a physiotherapist in the RAF. He spent 6 years in the Middle East with the RAF achieving the rank of Warrant Officer 1st class the highest rank available to an allied medical professional who is not a doctor.

At the end of hostilities he immigrated to South Africa and worked at the Johannesburg General Hospital for some time before starting in private practice in Jeppe Street in 1949. He was the first physiotherapist to utilise spinal manipulation in practice and became a resounding success.

Eddie was a great sportsman, having played both cricket and rugby for the RAF and in later years cricket and golf for the Wanderers Club. He was a founder member of Nomad's golf and was on the committee of the National Football
* stretching after practices and matches as preventative measures.

- The fact that the hockey coaches were not always aware of the injuries sustained by their players as well as of their players experiencing lower leg pain gives rise to concern as this has implications for the modifica tion of the training programme and the consequent progression of the injury. Specific education in sports injuries for coaches is needed and close liaison between the coach and player ought to be advocated. The coach should not hesitate to recommend the visit to a doctor or physiotherapist should basic treatment measures not result in improvement of the injury.

- Concerning rehabilitation after injury, most coaches realise the importance of physiotherapy, but lack knowledge about the importance of strength training and proprioceptive exercises.

\section{ACKNOWLEDGEMENTS}

The authors are indebted to the following people for their assistance and would like to express their gratitude to Sandra Jordaan, Karen Rosen-Allan, Hester van Aswegen and Leigh Hale, the Department of Biostatistics of the CSIR, as well as all the participating coaches and players.

Financial assistance for this project was provided by the Snaar Viljoen grant, University of the Witwatersrand.

\section{REFERENCES}

1. BrinerWB. Shinsplints. American Family Physi cian 1988;37(2):155-159.

2. Wadsworth $H$, Chanmugam APP. Electrophysical agents in physiotherapy. NSW: Science Press 1983:238.

3. Noakes TD, Granger S. Running Injuries. Oxford: Oxford University Press 1990:105-106.

4. Verow P. Injuries in Hockey. The Practitioner 1989;233:612-616

\section{League.}

Professionally, he was Chairman for many years of the Southern Transvaal branch of the SASP, was instrumental in founding the Private Practitioners Association of the Society and was its first Chairman. He was a driving force in organising the PPA to its present structure. With Pat Pilkington and Susie Oosthuizen he formed a formidable team which dealt with medical aid societies to set up tariff structures - much of which is still in use today. At the time of his death he was Honorary Life President of the PPA and attended the last Executive Committee meeting of the association in Bloemfontein.

He had a very strong character and held definite views on the value of physiotherapy maintaining that physiotherapists were grossly underpaid for their skill and expertise.

lam sure that all who knew him were sad to hear of his passing and will remember him with fond affection and respect for his enormous contribution to physiotherapy in South Africa. Our sympathies are extended to his wife, Jean and children, Gail and Anthony.
5. Matheson GO ct al. Stress fractures in athletes. The American Journal of Sports Medicine 1987;15(1):46-57.

6. Paty JG. Diagnosis and treatment of musculoskeletal running injuries. Seminars in Arthritis and Rheumatism 1988;18(1):48-60.

7. Mc Keag DB, Dolan C. Overuse syndromes of the lower extremity. Physiotherapy in Sport 1990;12(4):5-9.

8. Moore M. Shinsplints - diagnosis, management, prevention. Postgraduate Medicine 1988,83(1):199-210.

9. Reid DC. Sports Injury - Assessment and Rehabilitation. New York: Churchill Livingstone Inc. 1992:276.

10. Lehman WL. Overuse syndromes in runners. Ancrican Family Physician 1984;29(1):157-161.

11. Backx FJG, Erich WMB et al. Sports injuries in school-aged children - An epidemiologic study. The American Journal of Sports Medicine 1989;17(2):234-239.

12. Michael RH and Holder LE. The soleus syndrome - A cause of medial tibial stress (shin splints). The American Journal of Sports Me dicine 1985;13(2):87-94.

13. Viitasalo J, Kvist M. Some biomechanical aspects in the foot and ankle in athletes with and without shin splints. The American Journal of Sports Medicine 1983;11(3):125-130.

14. Bates B, Osternig L, Mason B. Foot orthotic devices to modify selected aspects of lower extremity biomechanics. American Journal of Sports Medicine 1979;7(6):338-342.

15. Garrick JG, Gillien DM, Whiteside P. The epidemiology of aerobic dance injury. The American Journal of Sports Medicine 1986;14(1):67-72

16. Peterson L, Renström P. Sport Injuries - Their prevention and treatment. Kenwyn: Juta and Co Ltd, 1986:16.

17. Roy S, Irvin R. Sports Medicine: Prevention, Evaluation, Management and Evaluation. New Jersey: Prentice Hall Inc., 1083:16-20.

18. Noakes T. Lore of Running. Cape Town: Oxford University Press, 1990:381.

\section{WORLD CONFEDERATION FOR PHYSICAL THERAPY CONGRESS}

\section{WASHINGTON, DC - JUNE 25 - 301995}

The American Physical Therapy Association is hosting the 1995 WCPT Congress to be held June 25-30, 1995 in Washington, DC. Although it is still two years before the Congress convenes, the Organising Committee is in the midst of planning a professionally stimulating Congress pre and post Congress courses and tours.

We are planning to have various types of presentations, so there will be something of educational interest for all member organisation participants. Of course, the social events will also be a highlight.

For further information contact: Ruth Wood, PT, Organising Chairman, WCPT Congress Registrar, American Physical Therapy Association, 1111 North Fairfax Street, Alexandria, Virginia 22314-1488, USA. 